\title{
Balance, functional mobility, and fall occurrence in patients with human T-cell lymphotropic virus type-1-associated myelopathy/tropical spastic paraparesis: a cross-sectional study
}

\author{
Erika Pedreira da Fonseca ${ }^{[1],[2],}$ Katia Nunes Sá ${ }^{[1],[2], ~ R e b e c a ~ F r e i t a s ~ R e i s ~ N u n e s ~}{ }^{[1]}$, \\ Antônio Carlos Ribeiro Junior ${ }^{[1]}$, Síntia Freitas Bastos Lira ${ }^{[1]}$ and Elen Beatriz Pinto ${ }^{[2]}$
}

[1]. Departamento de Fisioterapia, Universidade Católica do Salvador, Salvador, BA, Brasil.

[2]. Departamento de Pós-graduação, Escola Bahiana de Medicina e Saúde Pública, Salvador, BA, Brasil.

\begin{abstract}
Introduction: Human T-cell lymphotropic virus type-1-associated myelopathy/tropical spastic paraparesis (HAM/TSP) may lead to reduced functional mobility and balance. It is important to establish specific parameters that identify these changes and predict the risk of falls in these patients. The aim was to compare balance, functional mobility, and occurrence of falls among patients with and without HAM/TSP and to suggest values to predict the risk of falls in these patients. Methods: A crosssectional study in patients with and without HAM/TSP involved balance assessments based on the berg balance scale (BBS) and functional mobility evaluation based on the timed up and go (TUG) test. From reports of falls, the sensitivity, specificity, and best cutoff points for the risk of falls assessed by these instruments were established using the receiver-operating characteristic (ROC) curve; 5\% alpha was considered. Results: We selected 42 participants: 29 with HAM/TSP and 13 without HAM/TSP. There was a statistically significant difference in the occurrence of falls, balance, and functional mobility between the groups $(\mathrm{p}<0.05)$. Good accuracy was determined for the BBS (77\%) and TUG test $(70 \%)$ and the cutoff points for the risk of falls were defined as 50 points for the BBS and 12.28 seconds for the TUG test. Conclusions: Patients with HAM/TSP present reduced functional mobility and balance in relation to those without HAM/TSP. The risk of falls increased for these patients can be evaluated by the values of 50 points using the BBS and 12.28 seconds using the TUG test.
\end{abstract}

Keywords: Functional mobility. Balance. Falls. HTLV-1.

\section{INTRODUCTION}

Human T-cell lymphotropic virus type-1 (HTLV-1)associated myelopathy/tropical spastic paraparesis (HAM/TSP) is a neurological disorder caused by demyelination and axonal destruction of the spinal cord ${ }^{1-3}$. This health condition is more prevalent in women older than 40 years of age ${ }^{2-8}$. Patients with HAM/TSP have motor, sensory, and autonomic alterations, which may influence gait performance, balance maintenance, and functional mobility ${ }^{2-4}$. All these factors have an impact on the occurrence of falls ${ }^{9,10}$.

Body balance, because it is a functional ability, depends on motor and sensory factors ${ }^{1,9}$. Altered balance, as well as these factors, can affect functional mobility, since this depends on the ability to perform transfers and gait in a stable manner ${ }^{11}$.

Corresponding author: Msc Erika Pedreira da Fonseca

e-mail: erikapedreira@gmail.com

Received 11 October 2017

Accepted 26 March 2018
Studies report that the earliest clinical presentations of HAM/ TSP are reduction of muscle strength ${ }^{5,8,12-15}$ and spasticity in the lower limbs ${ }^{5,8,15}$. Muscle weakness occurs mainly in the hip flexors and ankle dorsiflexors, and spasticity mainly affects hip adductors and ankle plantiflexes ${ }^{8}$, which may have repercussions on balance reactions and functional mobility. These alterations may lead to a reduction in functional capacity, especially in the scope of mobility ${ }^{5}$. Most of these patients evolve to locomotion with some type of assistance $e^{5,8,12,14,16}$.

HAM/TSP remains a neglected health condition ${ }^{15}$, but deserves attention due to its functional repercussions. Few studies have previously addressed the issue, but balance and functional mobility were not evaluated simultaneously in patients with HAM/TSP. Therefore, the present study becomes relevant, and may help to delineate the functional profile of these patients, as well as suggest values that predict the risk of falls. Therefore, the aims of this study were to compare balance, functional mobility, and the occurrence of falls among patients with and without HAM/TSP and to suggest values to predict the risk of falls in patients with HAM/TSP. 


\section{METHODS}

A cross-sectional study was conducted between March and December 2016, with patients with a confirmed diagnosis of HAM/TSP according to the criteria of the World Health Organization $^{17}$, who attended a reference center for assistance and research on family members and were infected with HTLV1 in the city of Salvador, Bahia, Brazil. This study included individuals of both sexes, aged between 18 and 65 years, who had independent gait, with or without using a walking aid. Those with amputated limbs, psychiatric disorders, rheumatic or orthopedic diseases, and other associated neurological disorders, which could influence balance and functional mobility, as well as pregnant women, were excluded.

An evaluation was conducted in a single moment, when were evaluated sociodemographic and clinical data, balance, and functional mobility. Balance was evaluated using the Berg Balance Scale (BBS) ${ }^{18}$, and functional mobility using the Timed Up and Go (TUG) test ${ }^{11}$. The BBS consists of 14 items that evaluate body balance based on the execution of activities that require the maintenance of postural control. Each item is scored from 1 to 4, with the scale including a total of 54 points, and there is no previous cutoff point to forecast the risk of falls for patients with HAM/TSP. To perform the TUG test, the individual initiates the sit-up test, stands up after the examiner's command, walks three meters as previously marked, returns, and sits down. This activity was timed with the aid of a chronometer of the brand Herweg®.

The occurrence of falls in the last three months was investigated, with falls being defined as inadvertently remaining on the ground or at a lower level, excluding intentional changes in position to support furniture, walls, or other objects ${ }^{19}$. Participants were categorized as fallers when they reported two or more episodes of falls. Reports of falls were used to identify the cutoff points for the BBS and TUG test among the fallers.

The database was established using Microsoft Excel and analyzed using R v.3.1.3 software. Descriptive analysis was performed to identify the general and specific characteristics of the studied samples using absolute and relative frequencies for qualitative variables, such as sex; mean and standard deviation for quantitative variables of normal distribution, such as age and mediation; and quartiles for non-normal distribution variables. To verify the normality of the data distribution, we used the Shapiro-Wilk test.

To verify the existence of associations between the qualitative variables, we used Fisher's exact test and among the quantitative variables according to the study groups, we used the Student's t test or non-parametric Mann-Whitney U test when the distribution was non-normal. To identify the cutoff points that maximized sensitivity and specificity for the BBS and TUG test, for patients with HAM/TSP, we generated receiver-operating characteristic (ROC) curves. The significance level established for this study was 5\%.

According to the online calculator of the Laboratory of Epidemiology and Statistics of the University of São Paulo (LEE), using a standard deviation of 3 , a difference to be detected in 3 seconds between the values of the TUG test, ${ }^{20}$ adopting alpha of $5 \%$ and study power of $80 \%$, allowed for the estimation of a sample of 12 participants in each group.

\section{Ethical considerations}

This project is part of a major project, approved by the Research Ethics Committee, with CAAE 49634815.2.0000.5628. Signatures of consent from the participants were required, based on the 466/12 Resolution of Brazilian Council of Health.

\section{RESULTS}

We selected 42 participants: 29 with HAM/TSP and 13 without HAM/TSP. The analyses of the sociodemographic and clinical characteristics are presented in Table 1, where it is possible to observe that there were no statistically significant differences between the groups, except for the use of walking aids, which confirms the homogeneity among them for viability of the comparisons.

There were differences between patients with and without HAM/TSP in relation to the occurrence of falls (Table 2).

TABLE 1: Demographic and clinical characteristics of 42 participants with and without HAM/TSP.

\begin{tabular}{|c|c|c|c|c|}
\hline \multirow[b]{2}{*}{ Variable } & \multirow[b]{2}{*}{ Total $(n=42)$} & \multicolumn{3}{|c|}{ HAM/TSP } \\
\hline & & with ( $n=29)$ & without $(n=13)$ & $P$ value \\
\hline \multicolumn{5}{|l|}{ Age (years) } \\
\hline average/SD* & $51.02 \pm 9.83$ & $51.79 \pm 10.05$ & $49.31 \pm 9.48$ & 0.456 \\
\hline \multicolumn{5}{|l|}{ Gender, n (\%) ${ }^{* *}$} \\
\hline female & $29(69.04)$ & $19(65.5)$ & $10(76.9)$ & 0.719 \\
\hline Use of walking aids, $n(\%)^{* *}$ & $16(38.1)$ & $16(55.17)$ & 0 & 0.001 \\
\hline Brown skin color, $\mathrm{n}(\%)^{\star *}$ & $20(47.7)$ & $13(44.82)$ & $7(53.84)$ & 0.197 \\
\hline
\end{tabular}


TABLE 2: Occurrence of falls (intergroups).

$\mathrm{HAM} / \mathrm{TSP}$

\begin{tabular}{lcc} 
Occurence of falls, $\mathbf{n}(\%)$ & with $(\mathbf{n}=\mathbf{2 9})$ & without $(\mathbf{n = 1 3})$ \\
\hline None & $3(10.3)$ & $8(61.5)$ \\
One & $4(13.7)$ & $2(15.3)$ \\
Two & $1(3.4)$ & $1(7.6)$ \\
More than two & $21(72.4)$ & $2(15.3)$
\end{tabular}

HAM/TSP: human T-cell lymphotropic virus type-1-associated myelopathy/tropical spastic paraparesis. Fisher's exact test, P=0.001.

The ROC curve was constructed to show the association between the BBS and TUG scores and the occurrence of selfreported falls (Figure 1). The accuracy measured by the area under the curve was $77 \%$ for the BBS and $70 \%$ for the TUG test, with a sensitivity of $96.2 \%$ and specificity of $66.7 \%$ for the BBS and a sensitivity of $84.62 \%$ and specificity of $66.7 \%$ for the TUG test.

There was a major difference between the groups regarding the performance of balance and functional mobility (Table 3), and in relation to the risk of falls. Figure 2 indicates the risk of falls, determined based on the BBS (89.7\%) and TUG test $(79.3 \%)$.

\section{DIscussion}

In the present study, it was observed that patients with HAM/ TSP were female, older than 40 years, and with necessity of some aid for locomotion. These findings are consistent with the sociodemographic and clinical profile found in previous studies $^{5,7,8,12}$. Some authors suggest that many patients with symptomatic HAM/TSP may even require wheelchairs ${ }^{12,14}$.

It was verified that these individuals, when compared with patients without HAM/TSP, present balance deficits, reduced functional mobility, and a greater occurrence of falls. In addition, it was possible to establish a cutoff point for the prediction of falls, based on the BBS and TUG test. The mean values in the study participants obtained using these scales, the cut-off points, and the occurrence of falls reported in the 3-month period showed that the risk of falls is high in this population.

The significant occurrence of falls in this population was previously reported ${ }^{21}$, as it is also pointed out as a major event with severe complications in patients with multiple sclerosis (MS), an equally demyelinating disease ${ }^{22}$. This may be because some of the muscles most affected by the disease are responsible for balance reactions ${ }^{8,21}$.

The deficit in body balance evidenced by patients with myelopathy can occur due to reduced muscle strength ${ }^{5,8,13}$, and spasticity in the lower limbs ${ }^{5,8,14}$. With reduced muscle strength, there is a greater dependence on the performance of functional activities $^{5}$. Authors have pointed to the presence of sensory alterations, which may further compromise the maintenance of postural control ${ }^{8,23-25}$. In addition, some studies address the probable occurrence of associated brain lesions, which may affect motor control deficits ${ }^{26}$.

Functional mobility is dependent on several factors, including gait and transfer ability, balance, and muscle strength $^{11}$, and all these factors are compromised in these patients $^{8,14}$. It has been found that mobility becomes one of the greatest difficulties for these patients ${ }^{5}$, and it was identified that more than $70 \%$ of women with HAM/TSP exhibited reduced mobility and locomotion ${ }^{12}$.

To obtain a reference value that identifies the risk of falls in patients with HAM/TSP, cutoff points were established for the BBS and TUG test. These values become important in that they can identify patients who are most likely to experience falls. These may serve as parameters for earlier rehabilitation, since it has been observed that people with HTLV-1 can present with motor and sensory alterations, even without the development of $\mathrm{HAM} / \mathrm{TSP}^{13,15}$. Comparable values were established to detect clinical significance in patients with MS: 47 points for the BBS and 10.6 seconds for the TUG test ${ }^{27}$. Although the best mode of study to establish cutoff points is longitudinal, data on falls recorded in cross-sectional studies may establish a reference value, even if it is provisional.

Thus, the importance of these patients to be included in rehabilitation programs to improve balance and functional mobility and reduce the occurrence of falls is highlighted. Some treatment protocols have already been proposed ${ }^{18,27,28}$, but new clinical trials are still needed to determine effective rehabilitation strategies to improve functional mobility and balance in these patients.

This study had the advantages of presenting the balance and functional mobility profiles of patients with HAM/TSP, with 


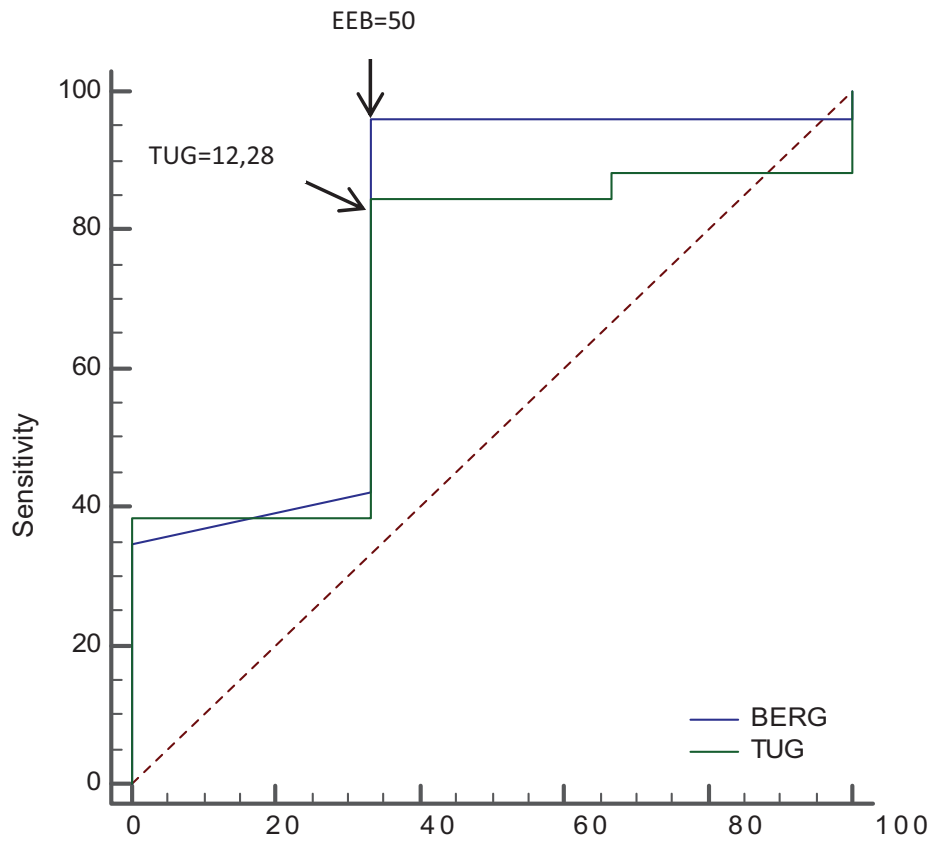

100- Specificity

$$
\begin{aligned}
& \text { Area under ROC curve }=66 \%(95 \% \mathrm{Cl}=58-90 \%) \\
& \text { Optimum cutoff point }=50 \\
& \text { Sensitivity }=96 \%(95 \% \mathrm{Cl}=80-99 \%) \\
& \text { Specificity }=66 \%(95 \% \mathrm{Cl}=9-99 \%)
\end{aligned}
$$

$$
\begin{aligned}
& \text { Area under ROC curve }=70 \%(95 \% \mathrm{Cl}=51-86 \%) \\
& \text { Optimum cutoff point }=12.28 \mathrm{~s} \\
& \text { Sensitivity }=84 \%(95 \% \mathrm{Cl}=65-95 \%) \\
& \text { Specificity }=66 \%(95 \% \mathrm{Cl}=9-99 \%)
\end{aligned}
$$

*BBS: berg balance scale

*TUG: timed up and go

FIGURE 1: ROC curve of association between BBS and TUG and occurrence of falls. TUG: timed up and go; ROC: receiver-operating characteristic; BBS: berg balance scale; Cl: confidence interval.

TABLE 3: Performance of balance and functional mobility intergroups. with and without HAM/TSP.

\begin{tabular}{lccc}
\hline & \multicolumn{3}{c}{ HAM/TSP } \\
\cline { 2 - 4 } Variable & with $(\mathrm{n}=29)$ & without $(\mathrm{n}=13)$ & P value \\
\hline Median/quartiles & & & \\
BBS* & $40(36-48)$ & $55(55-56)$ & $<0.001$ \\
TUG* & $17.5(12.8-27.2)$ & $8.5(7.8-8.9)$ & $<0.001<$
\end{tabular}

HAM/TSP: human T-cell lymphotropic virus type-1-associated myelopathy/tropical spastic paraparesis; BBS: berg balance scale; TUG: timed up and go. *Mann-Whitney. 


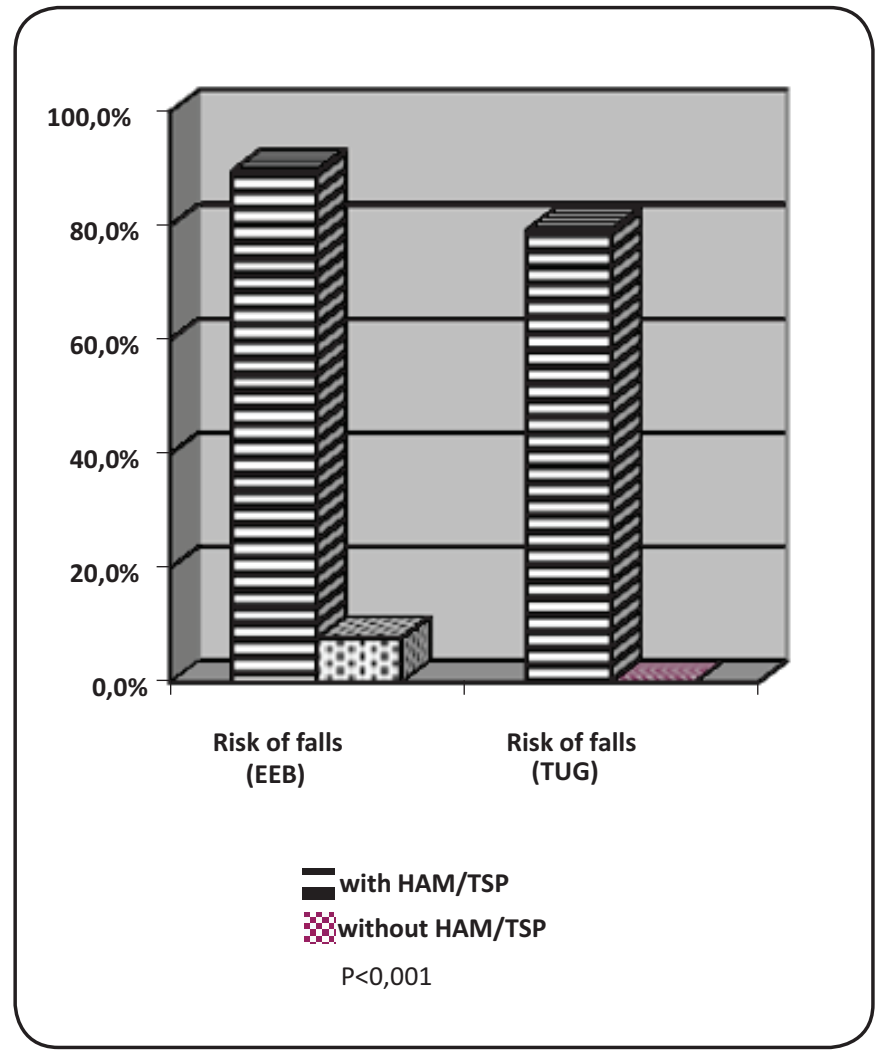

FIGURE 2: Risk of falls intergrouped based on the BBS and TUG test, in patients with and without HAM/TSP. TUG: timed up and go; HAM/TSP: human T-cell lymphotropic virus type-1-associated myelopathy/ tropical spastic paraparesis; BBS: berg balance scale. "Fisher's exact test.

the inclusion of a comparison group of individuals without the disease. In addition, the cutoff point for established fall hazards may facilitate the identification of possible fallers. However, it is necessary that longitudinal studies be performed to validate the proposed cutoff points for the prediction of falls over time.

Accordingly, it can be concluded that patients with HAM/ TSP present with balance deficits, reduced mobility, and a higher occurrence of falls, when compared to those without myelopathy. The cutoff points for the risk of falls established for this population were 50 points for the BBS and 12.28 seconds for the TUG test.

\section{Conflicts of interest}

The authors declare that there is no conflict of interest.

\section{REFERENCES}

1. Moxoto I, Boa-Sorte N, Nunes C, Mota A, Dumas A, Dourado I, et al. Sociodemographic, epidemiological and behavioral profile of women infected with HTLV-1 in Salvador, Bahia, and endemic área for HTLV. Rev Soc Bras Med Trop. 2007;40(1):37-41.

2. Yamano Y, Sato T. Clinical pathophysiology of human T-lymphotropic virus-type 1-associated myelopathy/tropical spastic paraparesis. Kawasaki. 2012;9(3):389.
3. Ribas J, Melo G. Human T-cell lymphotropic virus type 1 (HTLV-1)-associated myelopathy. Rev Soc Bras Med Trop. 2002;35(4):377-84.

4. Franzoi A, Araújo A. Disability profile of patients with HTLV-I associated myelopathy/tropical spastic paraparesis using the Funcional Independence Measure (FIM). Spinal Cord. 2005;43(4):236-40.

5. Caiafa RC, Orsini M, Felicio LR, Puccioni-Sohler M. Muscular weakness representes the main limiting fator of walk, functional Independence and quality of life of myelopathy patients associeted to HTLV-1. Arq Neuropsiquiatr. 2016;74(4):280-6.

6. Gessain A, Cassar O. Epidemiological aspects and world distribution of HTLV-1 infection. Front Microbiol. 2012;3:1-23.

7. Martin F, Inoue E, Cortese ICM, Kruschewsky RA, Adonis A, Grassi MFR, et al. Timed walk as primary outcome measure of treatment response in clinical trials for HTLV-1-associated myelopathy: a feasibility study. Pilot feasibility Stud. 2015;1:35. doi: 10.1186/s40814-015-0031-1

8. Cartier L, Araya F, Castillo JL, Ruiz F, Gormaz A, Tajima K. Progessive spastic paraparesis associated with human T-cell leucemia vírus type I (HTLV-I). Intern Med. 1992;31(11):1257-61.

9. Horak FB, Henry SM, Shumway-Cook A. Postural pertubations: new insights for treatment of balance disorders. Phys Ther. 1997;77(5):517-33.

10. Shumway-cook A, Horak FB. Assessing the influence of sensory interaction on balance: suggestion from the field. Phys Ther. 1986;66(10):1548-50.

11. Podsiadlo D, Richardson S. The Timed "Up \& Go": A Test of Basic Functional Mobilitv for Frail Elderlv Persons. JAGS 1991;39:142-8.

12. Coutinho IJ, Castro-Galvão B, Lima J, Castello C, Eiter D, Grassi MFR. Impacto da mielopatia associada ao HTLV/paraparesia espástica tropical (TSP/HAM) nas atividades de vida diária (AVD) em pacientes infectados pelo HTLV-1. Acta Fisiatr. 2011;18(1):6-10.

13. Caskey MF, Morgan DJ, Porto AF, Giozza SP, Muniz AL, Orge $\mathrm{GO}$, et al. Clinical manifestations associated with HTLV type I infection: a cross-sectional study. AIDS Res Hum Retroviruses. 2007;23(3):365-71.

14. Champs APS, Passos VMA, Barreto SM, Vaz LS, Ribas JGR. HTLV I myelopathy prognostic factors for total gait disability in patients with human T cell lymphotropic vírus I associated myelopathy: a 12-year follow-up study. Epidemiology. 2013;3:131.

15. Tanajura D, Castro N, Oliveira P, Neto A, Muniz A, Carvalho NB, et al. Neurological manifestations in human T-cell lymphotropic vírus type 1 (HTLV-1)-infected individuals without HTLV-1associated myelopathy/tropical spastic paraparesis: a longitudinal cohort study. Clin Infect Dis. 2015;61(1):49-56.

16. Gonçalves DU, Proietti FA, Barbosa-Stancioli EF, Martins ML, Ribas JG, Martins-Filho OA, et al. HTLV-1-associated myelopathy/ tropical spastic paraparesis (HAM/TSP) inflammatory network. Inflamm Allergy Drug Targets 2008;7(2):98-107.

17. World Health Organization (WHO). Human T lymphotropic vírus type, HTLV-1. Wkly Epidemiol Rec. 1988;64:382-3.

18. World Health Organization (WHO). Global report on falls prevention in older age. WHO Library Cataloguing-in-Publication Data ISBN 9789241563536 (NLM classification: WA 288). Genève: WHO; 2007. 53p.

19. Arnault V, Sá KN. Uso do Nintendo Wii em pacientes com HAM/ TSP: Ensaio clinico randomizado [Use of Nintendo Wii in patients with HAM/TSP: randomized clinical trial] [Masters thesis]. Salvador: Bahian School of Medicine and Human Health; 2014. 
20. Neto IF, Mendonça RP, Nascimento CA, Mendes SMD, Sá KN. Fortalecimento muscular em pacientes com HTLV-I e sua influência no desempenho funcional: um testudo piloto. Revistta Pesquisa em Fisioterapia 2012;2(2):143-55.

21. Acclimate LD, Araújo AQ, Chequer GL, due Azevedo MF, did Oliveira RVC, Lima A. Falls in patients with HTLV-I-associated myelopathy/tropical spastic paraparesis (HAM/TSP). Spinal Cord. 2013;51(3):222-5.

22. Malamud R, Murchison C, Bourdette D, Cameron M. Falls in people with multiple sclerosis compared with falls in healthy controls. Plos One. 2014;9(9):1-7.

23. Castillo JL, Cea JG, Verdugo RJ, Cartier L. Sensory dysfunction in HTLV-I-associated myelopathy/tropical spastic paraparesis. Eur Neurol. 1999;42:17-22.
24. 24. Leite ACC, Silva MTT, Alamy AH, Afonso CRA, Lima MAD, Andrada-Serpa MJ, et al. Peripheral neuropathy in HTLV-I infected individuals without tropical spastic paraparesis/HTLV-I-associated myelopathy. J Neurol. 2004;251(7):877-81.

25. Moritoyo H, Arimura K, Arimura Y, Tokimura Y, Rosales R, Osame M. Study oj lower limb somatosensory evoked potentials in 96 cases of HTLV-I-associated myelopathy/tropical spastic paraparesis. J Neurol Sci. 1996;138(1-2):78-81.

26. Araujo AQC, Silva MTT. The HTLV-1 neurological complex. Lancet Neurol. 2006;5(12):1068-76.

27. Learmonth YC, Paul L, McFadyen AK, Mattison P, Miller L. Reliability and clinical significance of mobility and balance assessments in multiple sclerosis. Int J Rehabil Res. 2012;35(1):69-74.

28. Britto VLS, Correa R, Vicent MB. Proprioceptive neuromuscular facilitation in HTLV-I-associated myelopathy/tropical spastic paraparesis. Rev Soc Bras Med Trop. 2014;47(1):24-9. 